\title{
QPRT: a potential marker for follicular thyroid carcinoma including minimal invasive variant; a gene expression, RNA and immunohistochemical study

\author{
Nora Hinsch*1, Matthias Frank ${ }^{1}$, Claudia Döring ${ }^{1,2}$, Christian Vorländer ${ }^{3}$ and \\ Martin-Leo Hansmann ${ }^{1}$
}

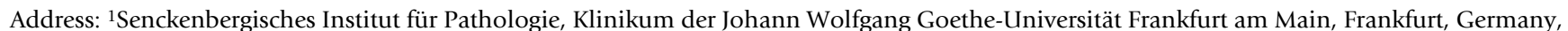 \\ 2Institut für Informatik, Johann Wolfgang Goethe-Universität Frankfurt am Main, Frankfurt, Germany and ${ }^{3} \mathrm{Abteilung}$ für Chirurgie, \\ Bürgerhospital Frankfurt am Main, Frankfurt, Germany \\ Email: Nora Hinsch* - n.hinsch@em.uni-frankfurt.de; Matthias Frank - matthias.frank@em.uni-frankfurt.de; \\ Claudia Döring - c.doering@em.uni-frankfurt.de; Christian Vorländer - C.vorlaender@buergerhospital-ffm.de; Martin- \\ Leo Hansmann - m.l.hansmann@em.uni-frankfurt.de \\ * Corresponding author
}

Published: 26 March 2009

BMC Cancer 2009, 9:93 doi:10.1/86/147/-2407-9-93

This article is available from: http://www.biomedcentral.com/I47/-2407/9/93

(C) 2009 Hinsch et al; licensee BioMed Central Ltd.

This is an Open Access article distributed under the terms of the Creative Commons Attribution License (http://creativecommons.org/licenses/by/2.0), which permits unrestricted use, distribution, and reproduction in any medium, provided the original work is properly cited.

\begin{abstract}
Background: The differential diagnosis between follicular thyroid adenoma and minimal invasive follicular thyroid carcinoma is often difficult for several reasons. One major aspect is the lack of typical cytological criteria in well differentiated specimens. New marker molecules, shown by polyor monoclonal antibodies proved helpful.
\end{abstract}

Methods: We performed global gene expression analysis of 12 follicular thyroid tumours (4 follicular adenomas, 4 minimal invasive follicular carcinomas and 4 widely invasive follicular carcinomas), followed by immunohistochemical staining of I 49 cases. The specificity of the antibody was validated by western blot analysis

Results: In gene expression analysis QPRT was detected as differently expressed between follicular thyroid adenoma and follicular thyroid carcinoma. QPRT protein could be detected by immunohistochemistry in $65 \%$ of follicular thyroid carcinomas including minimal invasive variant and only $22 \%$ of follicular adenomas.

Conclusion: Consequently, QPRT is a potential new marker for the immunohistochemical screening of follicular thyroid nodules.

\section{Background}

Differentiated thyroid carcinomas show an incidence of approximately $1 \%$ of all human malignancies [1]. In the group of endocrine malignant tumours they form, however, the largest entity. Differentiated thyroid carcinomas are a heterogeneous group composed of papillary, follicular (FTC) and medullary thyroid carcinoma [2]. In con- trast to papillary carcinoma, which usually can be easily diagnosed by its characteristic growth pattern und nuclear features, FTC can appear cytologically identical to follicular thyroid adenoma (FTA). In these cases only the growth pattern distinguishes between benign and malignant thyroid tumours. According to the grade of invasion, FTC can be subdivided in widely invasive FTC and minimal inva- 
sive FTC. These show a different clinical behaviour [3]. Histologically, minimal invasive FTC as well as widely invasive FTC are usually well differentiated tumours, lacking cytological atypia. The diagnosis of FTC is based on histological findings such as angioinvasion and/or invasion that penetrates the full thickness of the tumour-surrounding capsule [4].

To what extend these criteria are fulfilled in special cases may remain a matter of interpretation and provides a high inter- and even intraobserver variability $[5,6]$. In order to establish additional criteria for FTC molecular techniques such as sequencing and FISH $[7,8]$ were applied. These had limited value in discriminating FTC from FTA. RAS point mutations were evident in FTC as well as FTA, and chromosomal rearrangements (PAX8/PPAR $\gamma$-rearrangement) were seen in some FTC and FTA with a preference of FTC [9-11].

The aim of our study was the discovery of new helpful immunohistochemical markers for the detection and definition of FTC.

\section{Methods \\ Material}

Tissue of 4 FTA, 4 minimal invasive FTC and 4 widely invasive FTC was divided in two parts each. One part of the specimens was fixed in $4 \%$ buffered formalin and embedded in paraffin. The other part was snapfrozen in liquid nitrogen and stored at $-80^{\circ} \mathrm{C}$.

qRT-PCR: Fresh frozen material from 4 FTA and 4 FTC was used.

Tissue from 149 patients was available for immunohistochemistry for a retrospective study. 77 of these showed FTA and 72 FTC. Huerthle cell tumours were not included in this study. Western Blotting was performed by using fresh frozen tissue of 3 FTC and 3 FTA. The tissue of these 3 FTC was also taken for gene expression analysis.

Moreover, a prospective study of QPRT-expression with staining of 149 solitary thyroid nodules was undertalen. Of these 149 nodules, 75 were FTA, 51 nodular goiter, 9 oxyphilic FTA, 7 minimal invasive FTC and 7 others (Graves' disease, papillary thyroid carcinoma, diffuse goiter, or no nodule).

All specimen were originally submitted for diagnostic purposes and studied in accordance with national ethical principles and in compliance with the Helsinki declaration. Informed consent for the use of fresh frozen material in gene expression analysis was obtained from the patients. The study was approved by the ethics committee of the university hospital Frankfurt/Main.

\section{RNA-extraction}

RNA-extraction from fresh frozen tissue was performed using the RNAeasy Kit (Quiagen GmbH, Hilden, Germany) following the manufacturer's instructions. RNA quantity was measured using GeneQuant II photometer (Amersham Pharmacia Biotech, San Francisco, USA).

\section{Gene expression analysis}

Four biological replicates of FTC and FTA were used for gene expression profiling. Briefly, DIG-labeled cRNA was generated using $1 \mu \mathrm{g}$ total RNA per sample for amplification and labeling conducted according to manufacturer's instructions (Applied Biosystems RT-IVT Labeling Kit V.2.0 protocol). $10 \mu \mathrm{g}$ of the DIG-labeled cRNA were hybridized on Applied Biosystems Human Genome Survey Microarrays V.2.0 according to manufacturer's instructions (Applied Biosystems Chemiluminescence Detection Kit protocol Rev. D). Raw data from our microarray experiments have been deposited in Gene Expression Omnibus: $\quad$ http://www.ncbi.nlm.nih.gov/geo/query/ acc.cgi?acc $=$ GSE15045

\section{Immunohistochemistry}

Deparaffinized $5 \mu \mathrm{m}$ paraffin sections were used for all immunostainings. For dermatopontin immunostaining antigen retrieval was performed (30 minutes cooking in citrate buffer ( $\mathrm{pH}$ 6.0) in a microwave oven). For QPRT immunostaining, no antigen retrieval was necessary. The slides were treated with normal goat serum $(4 \mu \mathrm{g} / \mathrm{mL}$; Santa Cruz Biotechnology, Heidelberg, Germany), incubated at $4^{\circ} \mathrm{C}$ overnight applying the primary antibody dermatopontin (dilution 1:100, polyclonal antibody, Cat.Nr. 10537-1-AP, ProteinTech Group, Inc., Chicago, USA) or QPRT (dilution 1:200, clone 5D11, Abnova Corporation, Taipei, Taiwan). The Envision system with alkaline phosphatase and Fast Red (DAKO, Hamburg, Germany) was used. Tonsils with follicular hyperplasia where used as positive controls. For negative controls, no antibody was added.

The following criteria were applied to evaluate the immunostained sections:In positive cases, at least $10 \%$ of tumour cells had to show a cytoplasmatic immunoreaction. Most positive cases displayed positivity for more than $50 \%$ of the tumour cells. The staining pattern was heterogen. The percentage of positive cells was estimated in relation to negative tumour cells.

\section{TaqMan $^{\circledR}$ Quantitative real-time PCR}

QPRT expression was analyzed by a quantitative real-time RT-PCR (qRT-PCR) assay (Hs00204757_m1, Applied biosystems, Weiterstadt, Germany). Beta-2-microglobulin (B2M) was used as endogenous control (4326319E, Applied Biosystems) for relative quantification. qRT-PCR was performed using a 96-well tray on the AbiPrism 7900 
HT (Applied biosystems). The total reaction volume of 20 $\mu \mathrm{l}$ contained $1 \times$ TaqMan universal Mastermix, $1 \mu \mathrm{l}$ primer-probe mix and $5 \mu \mathrm{l}$ cDNA. The samples were tested twice as singleplex-PCR. Results were specified as RQvalue, and calculated with SDS 2.2.1 (Applied biosystems) (RQ $=2-\Delta \Delta \mathrm{C}_{\mathrm{t}} . \Delta \Delta \mathrm{Ct}$ is calculated as difference in $\Delta \mathrm{Ct}$ value between the sample and the reference sample)

\section{Western Blot analysis}

For western blotting snap frozen tumour tissue was lysed in 62.5 Tris- $\mathrm{HCl}, 2 \%$ SDS, 1.5\% $\beta$-mercaptoethanol, 9\% glycerol, $10 \mu \mathrm{g} / \mathrm{ml}$ leupeptin, $10 \mu \mathrm{g} / \mathrm{ml}$ aprotinin and $0.00125 \%$ bromophenol blue, cooked $10 \mathrm{~min}$, with intermitting stirring, and cooled on ice.

Cell-lysates were subjected to a 10-20\% SDS-PAGE (Criterion $^{\text {TM }}$ Pre-Cast Gel, Bio-Rad Laboratories GmbH, München, Germany) and electrotransferred onto a nitrocellulose membrane (Bio-Rad Immuno-Blot ${ }^{\mathrm{TM}}$ PVDF, BioRad). The membranes were incubated with the QPRT antibody (dilution $1: 1000$ ) at $4{ }^{\circ} \mathrm{C}$ overnight, followed by incubation with a horseradish-peroxidase-conjugated anti-mouse secondary antibody (dilution 1:2000, Code P0260, DAKO). For signal detection the chemiluminescence detection system ECL plus (Amersham Biosciences, Little Chalfont, UK) was used. Actin (C11, Santa Cruz Biotechnology) was used as loading control.

\section{Statistics}

Statistical analysis was performed with the statistical computing environment $\mathrm{R}$ [12]. Additional software packages (ab1700, rma, multtest) were taken from the Bioconductor project [13].

Probe level normalization was conducted using the quantile normalization method [14].

Probeset summarization was calculated using the robust median polish method [15] on the normalized data. For each probeset an additive robust additive model on the logarithmic scale (base 2) was fitted across the arrays, considering the different affinities of the probes via the probe effect. We used a global filter to reduce the dimension of the microarray data: We applied an intensity filter (the signal intensity of a probe set should be above 100 in at least 25 percent of the samples, if the group size is equal) and a variance filter (the interquartile range of $\log _{2}$ intensities should be at least 0.5).

p-values were calculated applying the two sample t-test (assuming equal variances in both groups) to identify genes that are differentially expressed between the two groups. We use the False Discovery Rate (FDR) [16] to account for multiple testing. Also Fold Changes (FC) between the two groups were calculated for each gene.
Differentially expressed genes were determined with pvalue, FDR and FC criteria.

Unsupervised hierarchical cluster analysis was performed with the agglomeration method "average". Manhattan method is used for the distance measure. Probe sets with a standard deviation more than one were included in the clustering. The results of immunohistochemical staining were analyzed with a Pearson's Chi-Square test, using SPSS 8.0 (SPSS Inc., Chicago, USA).

Sensitivity is defined as positive stained carcinomas in relation to all carcinomas included in the study. Specificity is the fraction of carcinomas in all positively immunostained samples.

\section{Results \\ Gene expression analysis}

Gene expression analysis was performed using 4 FTA, 4 widely invasive FTC and 4 minimal invasive FTC. In unsupervised hierarchical clustering 3830 probe sets with a standard deviation more than one over all samples were included. The adenomas formed one group in the cluster analysis (figure 1) whereas widely invasive FTC and minimally invasive each FTC clustered together. An exchange between the two groups occurred once: one widely invasive FTC clustered with the minimal invasive FTC and one minimal invasive FTC clustered with the widely invasive FTC. Unexpectedly the widely invasive FTC clustered closer to the FTA than to the minimal invasive FTC. FTA in comparison to minimal invasive and widely invasive FTC differed in 25 genes (FC $>5$ or $<-5$, p-value $<0.05$, see Additional file 1). For further analysis the genes with the strongest differential expression, namely dermatopontin (FC 12.6 and 39.5) and quinolinate phosphoribosyltransferase (QPRT, FC -6.0 and -5.0) were selected.

\section{Immunohistochemistry}

Immunohistochemical validation of the results of the gene expression analysis was performed in a two-step-procedure: first, both antibodies were tested in a set of 32 probes. According to gene expression analysis, dermatopontin should have been positive in FTA and QPRT in FTC. However, dermatopontin appeared to be of little use (59\% accuracy; 6 out of 17 positive FTA and 8 out of 15 positive FTC). Only QPRT was used with further 117 slides for a second step. Taken together, with QPRT a correct diagnosis according to our staining was reached in 107 out of 149 cases (72\%). The sensitivity was $65 \%$ (47/ $72)$, the specificity $73 \%(47 / 64)$. The positive predictive value was 0,73 , the negative predictive value was 0,71 . Divided into subgroups, the sensitivity in minimal invasive FTC $(60 \%)$ was lower than in widely invasive FTC $(75 \%)$. Results are shown in table 1 . Figure 2 shows an example of immunohistochemical staining. 


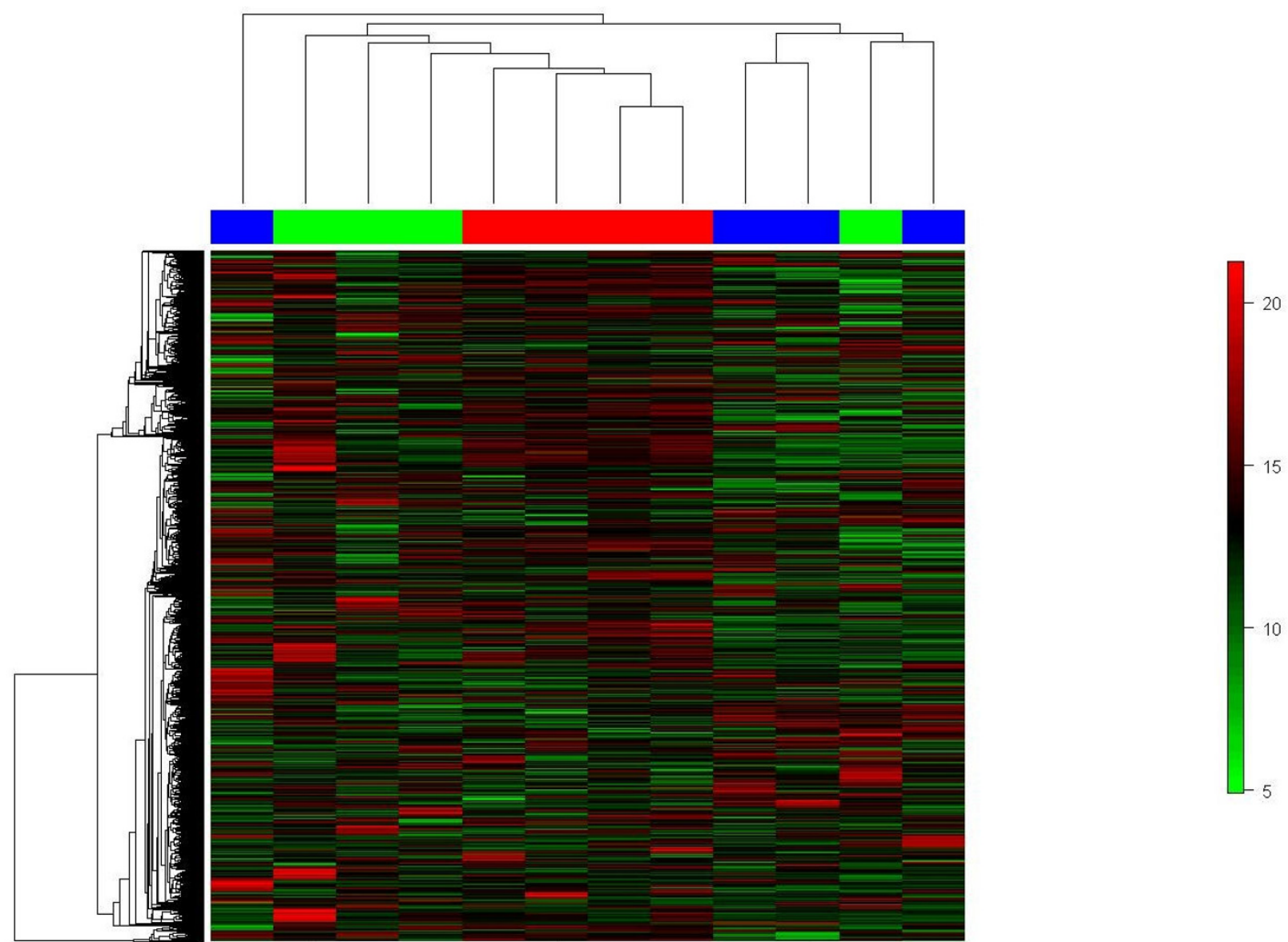

Figure I

Unsupervised clustering of 4 follicular adenomas (FTA), 4 minimal invasive follicular carcinomas (FTC) and 4 widely invasive FTC. The clustering was performed with 3830 genes. Adenomas cluster to one group, which is surprisingly located between widely and minimal invasive follicular carcinomas. One of the widely as well as the minimal invasive follicular carcinoma is located in the each other group. Red: FTA, green: widely invasive FTC, blue: minimal invasive FTC

In the prospective study, 59 out of 75 FTA were QPRT-negative $(78,7 \%)$, while 6 out of 7 minimal invasive FTC were positive $(85,7 \%)$. From the cases with nodular goiter, 14 out of 51 turned out to be positive $(27,4 \%)$, most cases

Table I: Tabular list of results of immunohistochemical QPRT staining.

\begin{tabular}{lccc}
\hline & \multicolumn{3}{c}{ Staining } \\
\hline FTA & + & - & Total \\
\hline minimal invasive FTC & 17 & 60 & 77 \\
\hline widely invasive FTC & 29 & 19 & 48 \\
\hline Total & 18 & 6 & 24 \\
\hline
\end{tabular}

Pearson Chi-Square $=28,4, p<0,0001$ showed a focal positivity, often in areas with oxyphilic metaplasia. In accordance with this observation, oxyphilic FTA showed a positivity in most of the cases ( 6 out of 9 , $66,7 \%)$. The other 7 cases included in this study were mostly negative (one oxyphilic FTC, two cases with Graves'disease, one papillary thyroid carcinoma, one diffuse goiter and one thyroid without nodules). Only one papillary thyroid carcinoma, follicullar variant stained positive.

\section{Western Blot}

Western blotting confirmed the specificity of the QPRTantibody. 3 FTA and 3 FTC were used for western blotting. Only the three FTC, but none of the FTA, showed a band at $34 \mathrm{kD}$ (Figure 3B).

\section{qRT-PCR}

qRT-PCR of FTC compared to FTA showed a $\Delta \Delta \mathrm{Ct}$ of 10,44 in FTC compared to 0,42 in FTA, indicating a nearly 


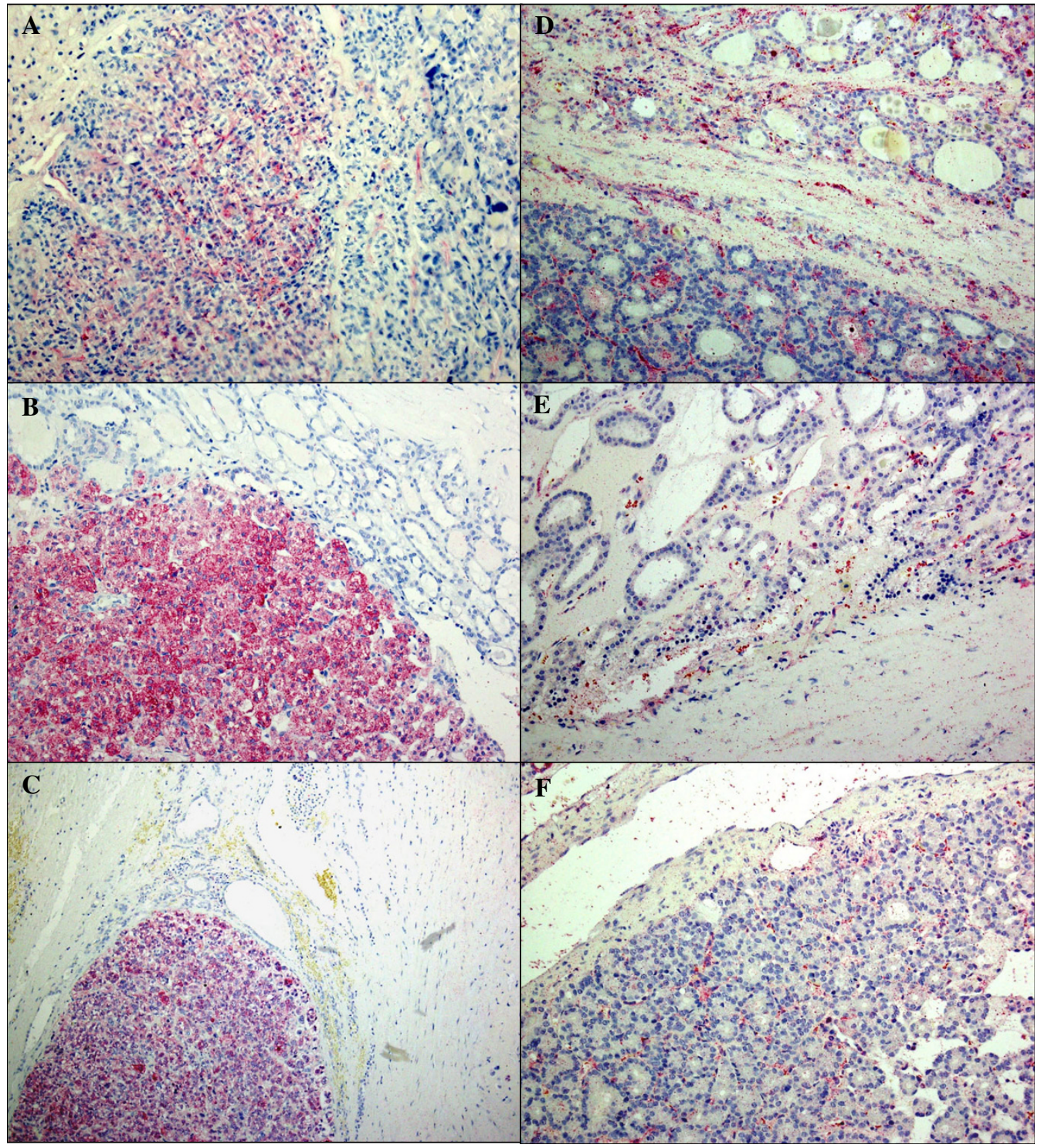

\section{Figure 2}

Representative picture of immunohistochemical staining of FTC (A-C) and FTA (D-F). Carcinoma tissue displays a cytoplasmatic staining of the tumour cells, while adenoma tissue remains unstained.

twenty times higher amount of QPRT-RNA in carcinoma tissue (Figure 3A).

\section{Discussion}

We performed gene expression analysis of 12 follicular thyroid tumours (4 FTA, 4 minimal invasive FTC and 4 widely invasive FTC) resulting in a list of 25 genes which differed highly in their FTC and FTA expressions. The most interesting gene was QPRT showing a significant 5 fold upregulation in FTC compared to FTA. In further immunohistochemical validation QPRT could be established as helpful in discriminating between FTA and FTC. In a ret- rospective study 47 out of 72 FTC were positively immunostained by this antibody. 60 out of 77 FTA were negative for QPRT. Further validation was performed by using qRT-PCR and western blotting. Both validation methods confirmed our immunohistochemical findings. In an additional prospective study with 149 cases, 78,8\% of FTA were stained negatively. $85,7 \%$ of minimal invasive FTC were stained positively with the QPRT-antibody. The potential value of this marker lies in the screening of thyroid nodules, with nodules staining positively being processed intensively. 
A

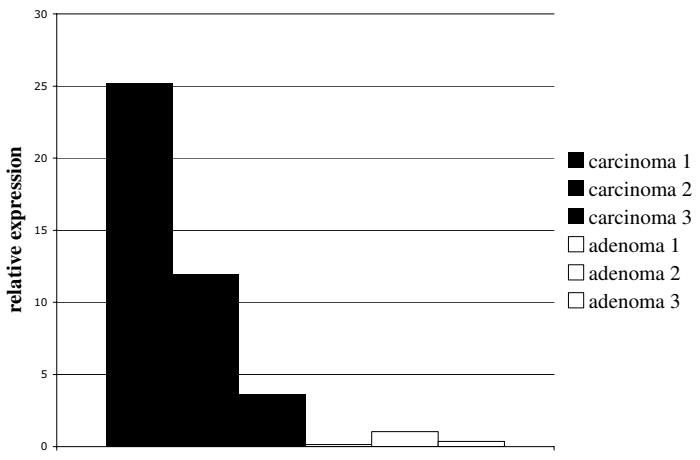

B
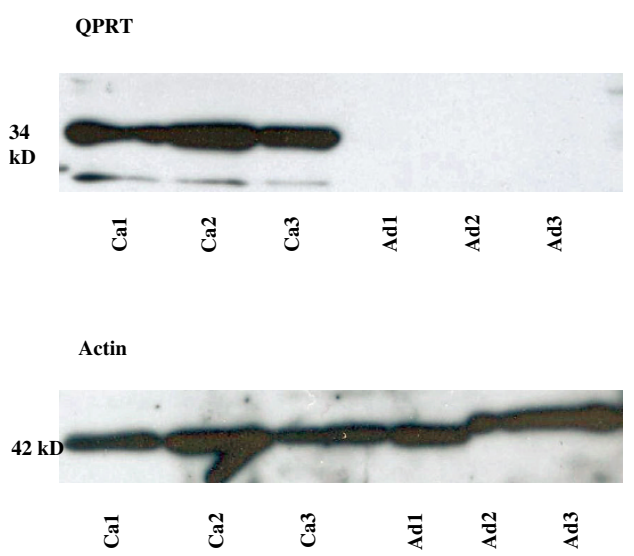

Figure 3

qRT-PCR (A) and western blot analysis (B) of the 3 FTA and FTC presented in figure 2. In QRT-PCR, carcinomas reveal a relative quantity of QPRT-RNA expression between 3,65 and 25, I8. The relative quantity of QPRT-RNA expression in adenomas is between 0,13 and $I, 00$. In western blot analysis, FTC reveal a strong band at $34 \mathrm{kD}$, while follicular adenomas lack any band. Blotting with actin was performed as loading control. Ad: Adenoma; Ca: Carcinoma.

QPRT is a $34 \mathrm{kD}$ [17] key enzyme in the catabolism of quinolinate in the tryptophan-nicotinamide adenine dinucleotide pathway. Quinolinate is an endogenous neurotoxin [18], which is non-enzymatically derived from alpha-amino-beta-carboxymuconate-semialdehyde (ACMS) [19]. It has been speculated that QPRT activity increases in response to neurodegenerative events [20]. QPRT has been described in the nucleus and cytoplasma [21] of cells of the human central nervous system and the liver [22] and in blood cells (platelets and erythrocytes) [23]. Gene expression analysis revealed a QPRT upregulation with a fold change of 3,6 in uterine leiomyoma [24]. So far, QPRT has not been linked to other human diseases besides neurodegenerative disorders. In addition, it is unknown if QPRT is important in carcinogenesis. Until now QPRT has not been described in human thyroid tissue.

Different techniques such as global gene expression analysis and SAGE-analysis have been used to define follicular thyroid carcinoma (see Additional file 2). [25-30] The authors cited above validated the established gene expression or SAGE-results by qRT-PCR. qRT-PCR was also used as classifier to distinguish between a set of few genes $[26,30]$ and gene trios [29], which were able to classify thyroid nodules correctly in between 83 and $96,7 \%$. Two publications reported additional immunohistochemical staining based on some factors provided by gene expression analysis $[26,30,31]$ resulting in 6 new immunohistochemical markers (see Additional file 2).

Of these markers, the two not commercially available antibodies integral membran proteine 1 (ITM1) and chromosome 1 open reading frame 24 (C1orf24) had the highest sensitivity of $100 \%$ [31]. Damage-inducible transcript 3 (DDIT3) and arginase II (ARG2) showed a high specificity with $85 \%$ positivity in carcinomas and only $9,4 \%$ positivity in adenomas [26].

Our gene expression results indicated, however, that no difference in gene expression between three of the four markers (ARG2, DDIT3 and ITM1), C1orf24 was present at our gene chip. One reason for this may be the different methodological approach. Cerutti et al. did SAGE-analysis of one FTC and one FTA. In contrast, we used the applied gene expression system at 12 follicular thyroid nodules. Furthermore, there was no statement of the number of minimal invasive FTC included in the study, and the total number of cases used for immunohistochemistry was limited to 27 carcinomas and 22 adenomas.

Other factors obtained by gene expression analysis and tested immunohistochemically were cyclin D2 (CCND2) and protein convertase 2 (PCSK2). A combination of these two factors resulted in a sensitivity of $89,5 \%$ and a specificity of $80,8 \%$.

Both factors were described as downregulated and consequently no immunostaining was found in FTC [30]. PCSK2 is, however, upregulated in FTC in gene expression analysis in two different studies $[26,28]$. Our global gene expression analysis also revealed a significant upregulation of PCSK2 in minimal invasive FTC compared to FTA. In addition, we found no significant difference in gene expression of PCSK2 between widely invasive FTC and FTA.

In several studies immunohistochemical markers for differentiating thyroid nodules were defined as independent from gene expression analysis. HBME-1, galectin-3 and 
CK19 were the markers most frequently referred to in literature and most commonly used for differentiating benign from malignant thyroid tumours. These markers showed, however, a low specificity for FTC. FTC was described as positive for HBME-1 in between 63 and $88 \%$, while FTA was positive in 55,6 until $48,6 \%$ of the cases. Galectin-3 showed a positivity between 21 and $64 \%$ in FTC compared to 11 until 2,9\% in FTA. CK19 also showed a low specificity with positivity in FTC in $21-44 \%$ and in FTA in 28,6 and $33 \%[32,23]$. Therefore these markers seemed unpractical for routine diagnosis.

Our approach differs significantly from other studies in tissue selection. We grouped minimal invasive FTC from widely invasive FTC and FTA. Moreover we used only genes for further analysis, which were significantly differently regulated in the group of minimal invasive FTC and widely invasive FTC. Another major difference was the method used for gene expression. The articles mentioned above relied on SAGE-analysis, self-designed DNA-microarrays, with a number of genes between 3200 and 7458 [27-29], or affymetrix U95A or 133A oligonucleotid arrays $[25,30]$. We used oligonucleotide gene expression analysis from applied biosystems, which had, to our knowledge, not been used for analysis of follicular thyroid carcinoma before. This may explain why there was no overlap between the genes reported to be differently expressed as well as the set of genes we found. Another difference was the way of validating the gene expression analysis. We focussed on immunohistochemical staining, using a large set of follicular tumours. Therefore we concentrated on genes with high expression differences between FTC and FTA to find a gene suitable for immunohistochemical staining.

\section{Conclusion}

In conclusion, gene expression analysis revealed a new immunohistochemical marker, which may be helpful in differentiating FTC from FTA. QPRT is a potential useful marker for immunohistochemical screening analysis of solitary thyroid nodules. In case of positivity the lesion should be processed extensively. This procedure probably reduces the number of misdiagnosed or overlooked minimal invasive carcinomas. The sensitivity of the new monoclonal antibody is, however, limited. For this reason, QPRT as other new markers has the highest diagnostic relevance if it is applied not solitary but in combination. Additional prospective studies of fine needle aspirates should be included.

\section{Competing interests}

The authors declare that they have no competing interests.

\section{Authors' contributions}

$\mathrm{NH}$ carried out the immunohistochemical, the real-time PCR studies as well as drafted the manuscript. MF carried out the gene expression analysis. CD performed the statistical analysis. CV gathered the material. MLH conceived of the study, and participated in its design and coordination and helped in drafting the manuscript. All authors read and approved the final manuscript.

\section{Additional material}

\section{Additional file 1}

List of genes significantly differing between follicular thyroid adenoma and carcinoma.

List of genes with a fold change $>5$ or $<-5$, and a p-value $<0,05$. SDAd/ $S D C a \_F C$ is the fold change of the gene expression in follicular thyroid adenoma (FTA) in relation to follicular thyroid carcinoma (FTC). SDAd/ SDCami_FC is the fold change of the gene expression in FTA in relation to minimal invasive FTC. QPRT is the only gene in this list which is upregulated in FTC, the other genes are downregulated in FTC.

Click here for file

[http://www.biomedcentral.com/content/supplementary/14712407-9-93-S1.xls]

\section{Additional file 2}

Comparison of studies concerning the discrimination of FTC and FTA using gene expression analysis

Excel file comparing different published studies concerning the discrimination of FTC and FTA using gene expression analysis.

Click here for file

[http://www.biomedcentral.com/content/supplementary/14712407-9-93-S2.xls]

\section{Acknowledgements}

This study was supported by the Senckenbergische Stiftung Frankfurt/Main. We thank Ralf Lieberz for expert technical assistance and Dr. Christoph Renne for critical reading and discussion of this manuscript.

\section{References}

I. Stewart BW, Kleihues P: Thyroid cancer. In World cancer report Edited by: Stewart BW, Kleihues P. Lyon: IARC Press; 2003:257-260.

2. Hoelzer S, Steiner D, Bauer R, Reiners C, Farahati J, Hundahl SA, Dudeck J: Current practice of radioiodine treatment in the management of differentiated thyroid cancer in germany. Eur J Nucl Med 2000, 27: I 1465-I 472.

3. Schmid KW, Farid NR: How to define follicular thyroid carcinoma? Virchows Arch 2006, 448:385-393.

4. DeLellis RA, Lloyd R, Heitz PU, Eng C, (Eds): WHO histological classification of thyroid and parathyroid tumour. In World Health Organization classification of tumours. Pathology and genetics. Tumours of endocrine organs Lyon: IARC Press; 2004:49-123.

5. Franc B, de la Salmoniere $P$, Lange $F$, Hoang $C$, Louvel A, de Roquancourt A, Vildé F, Hejblum G, Chevret S, Chastang C: Interobserver and intraobserver reproducibility in the histopathology of follicular thyroid carcinoma. Hum Pathol 2003, 34:1092-1100.

6. Hirokawa M, Carney JA, Goellner JR, DeLellis RA, Heffess CS, Katoh $R$, Tsujimoto $M$, Kakudo $K$ : Observer variation of encapsulated follicular lesions of the thyroid gland. Am J Surg Pathol 2002, 26: $1508-|5| 4$.

7. Chung KW, Yang SK, Lee GK, Kim EY, Kwon S, Lee SH, Park do J, Lee HS, Cho BY, Lee ES, Kim SW: Detection of BRAFV600E mutation on fine needle aspiration specimens of thyroid nodule refines cyto-pathology diagnosis, especially in BRAF600E mutation-prevalent areas. Clin Endocrinol (Oxf) 2006, 65:660-666. 
8. Hibi $Y$, Nagaya $T$, Kambe F, Imai T, Funahashi H, Nakao A, Seo H: Is thyroid follicular cancer in Japanese caused by a specific $t(2 ; 3)(q 13 ; p 25)$ translocation generating Pax8-PPAR fusion mRNA? Endocr J 2004, 5 I:36I-366.

9. Lacroix L, Mian C, Barrier T, Talbot M, Caillou B, Schlumberger M, Bidart JM: PAY8 and peroxisome proliferator-activated receptor gamma I gene expression status in benign and malignant thyroid tissues. Eur J Endocrinol 2004, I 5 I:367-374.

10. Marques AR, Espadinha C, Catarino AL, Moniz S, Pereira T, Sobrinho LG, Leite V: Expression of PAX8-PPAR gamma I rearrangements in both follicular thyroid carcinomas and adenomas. $J$ Clin Endocrin Metab 2002, 87:3947-3952.

11. Nikiforova MN, Lynch RA, Biddinger PW, Biddinger PW, Alexander EK, Dorn GW 2nd, Tallini G, Kroll TG, Nikiforov YE: Ras point mutations and PAX8-PPAR gamma rearrangements in thyroid tumours: evidence for distinct molecular pathways in thyroid follicular carcinoma. J Clin Endocrin Metab 2003, 88:23।8-2326.

12. R Development Core Team: $R: A$ language and environment for statistical computing. [computer program] R Foundation for Statistical Computing, Vienna, Austria; 2005.

13. Gentleman RC, Carey VJ, Bates DM, Bolstad B, Dettling M, Dudoit S, Ellis B, Gautier L, Ge Y, Gentry J. Hornik K, Hothorn T, Huber W, lacus S, Irizarry R, Leisch F, Li C, Maechler M, Rossini AJ, Sawitzki G, Smith C, Smyth G, Tierney L, Yang JY, Zhang J: Bioconductor: Open software development for computational biology and bioinformatics. Genome Biology 2004, 5:R80.

14. Tukey JW: Exploratory Data Analysis Reading Massachusetts: AddisonWesley; 1977.

15. Benjamini $Y$, Hochberg $Y$ : Controlling the false discovery rate: a practical and powerful approach to multiple testing. J R Statist Soc B 1995, 57:289-300.

16. Bolstad B, Irizarry R, Strand M, Speed T: A comparison of normalization methods for high density oligonucleotide array data based on variance and bias. Bioinformatics 2003, 19:185-193.

17. Moore D, Bice T, Jin L, Grandhi A, DeLucas LJ, Narayana SV: Crystallization and preliminary crystallographic investigation of porcine quinolinate phosphoribosyltransferase. Acta Crystallogr D Biol Crytallogr 1998, 54:1 19-120.

18. Stone TW, Perkins MN: Quinolinic acid: a potent endogenous excitant at amino acid receptors in CNS. Eur J Pharmacol I98I, 72:4II-4I2.

19. Fukuoka S, Ishiguro K, Yanagihara K, Tanabe A, Egashira Y, Sanada H, Shibata K: Identification and expression of a cDNA encoding human alpha-amino-beta-carboxymuconate-epsilon-semialdehyde decarboxylase (ACMSD). A key enzyme for the tryptophan-niacin pathway and "quinolinate hypothesis". J Biol Chem 2002, 277:35162-35167.

20. Foster AC, Whetsell WO, Bird ED, Schwarcz R: Quinolinic acid phosphoribosyltransferase in human and rat brain: activity in Huntigton's disease and in quinolinate-lesioned rat striatum. Brain Res 1985, 336:207-214.

21. Köhler C, Eriksson LG, Flood PR, Hardie JA, Okuno E, Schwarcz R: Quinolinic acid phosphoribosyltransferase: preferential glial localization in the rat brain visualized by immunocytochemistry. Proc Natl Acad Sci 1987, 84:349I-3495.

22. Okuno E, White RJ, Schwarcz R: Quinolinic acid phosphoribosyltransferase: purification and partial characterization from human liver and brain. J Biochem 1988, 103:1054-1059.

23. Foster AC, Schwarcz R: Characterization of quinolinic acid phosphorybosyltransferase in human blood and observations in Huntington's disease. J Neurochem 1985, 45:199-205.

24. Arslan AA, Gold LI, Mittal K, Suen TC, Belitskaya-Levy I, Tang MS, Toniolo P: Gene expression studies provide clues to the pathogenesis of uterine leiomyoma: new evidence and a systematic review. Hum Rep 2005, 20:852-863.

25. Barden CB, Shister KW, Zhu B, Guiter G, Greenblatt DY, Zeiger MA, Fahey TJ 3rd: Classification of follicular thyroid tumors by molecular signature: results of gene profiling. Clin Cancer Res 2003, 9: $1792-1800$

26. Cerutti JM, Delcelo R, Amadei MJ, Nakabashi C, Maciel RM, Peterson B, Shoemaker J, Riggins G]: A preoperative diagnostic test that distinguishes benign from malignant thyroid carcinoma based on gene expression. J Clin Invest 2004, I I 3: 1 234- I 242.

27. Fryknas M, Wickenberg-Bolin U, Göransson H, Gustafsson MG, Foukakis T, Lee JJ, Landegren U, Höög A, Larsson C, Grimelius L, Wallin
G, Pettersson U, Isaksson A: Molecular markers for discrimination of benign and malignant follicular thyroid tumors. Tumor Biol 2006, 27:2।I-220.

28. Puskas LG, Juhasz F, Zarva A, Hackler L Jr, Farid NR: Gene profiling identifies genes specific for well-differentiated epithelial thyroid tumors. Cell Mol Biol 2005, 5 I: I77-186.

29. Stolf BS, Santos MM, Simao DF, Diaz JP, Cristo EB, Hirata R Jr, Curado MP, Neves EJ, Kowalski LP, Carvalho AF: Class distinction between follicular adenomas and follicular carcinomas of the thyroid gland on the basis of their signature expression. Cancer 2006, 106:1891-1900.

30. Weber F, Shen L, Aldred MA, Morrison CD, Frilling A, Saji M, Schuppert $F$, Broelsch CE, Ringel MD, Eng C: Genetic classification of benign and malignant thyroid follicular neoplasia based on a three-gene combination. I Clin Endocrin Metab 2005, 90:2512-2521.

31. Cerutti JM, Latini FR, Nakabashi C, Delcelo R, Andrade VP, Amadei MJ, Maciel RM, Hojaij FC, Hollis D, Shoemaker J, Riggins GJ: Diagnosis of suspicious thyroid nodules using four protein biomarkers. Clin Cancer Res 2006, I 2:33 | I-33 I8.

32. de Matos PS, Ferreira AP, de Oliveira Facuri F, Assumpção LV, Metze K, Ward LS: Usefulness of HBME-I, cytokeratin I9 and galectin-3 immunostaining in the diagnosis of thyroid malignancy. Histopathology 2005, 47:39I-40I.

33. Park YJ, Kwak SH, Kim DC, Kim H, Choe G, Park do J, Jang HC, Park SH, Cho BY, Park SY: Diagnostic value of galectin-3, HBME-I, cytokeratin 19, high molecular weight cytokeratin, cyclin D I and $\mathrm{p} 27 \mathrm{kipl}$ in the differential diagnosis of thyroid nodules. Korean Med Sci 2007, 22:621-6.

\section{Pre-publication history}

The pre-publication history for this paper can be accessed here:

http://www.biomedcentral.com/1471-2407/9/93/prepub

Publish with BioMed Central and every scientist can read your work free of charge

"BioMed Central will be the most significant development for disseminating the results of biomedical research in our lifetime. "

Sir Paul Nurse, Cancer Research UK

Your research papers will be:

- available free of charge to the entire biomedical community

- peer reviewed and published immediately upon acceptance

- cited in PubMed and archived on PubMed Central

- yours - you keep the copyright 